\title{
ASSAf turns 20: Young enough to be dynamic and old enough to be trusted with its mission
}

Some national science academies boast of their long histories, and (to adapt in a more positive direction Churchill's malicious gibe about the modesty of his political opponent Attlee) they mostly have a lot to be boastful about. If longevity is to be the main criterion on which the merits of an academy are to be determined, however, the case for starting a new one would be weak. The fact that the 'academy idea' has by now taken root in a majority of UN member nations, and the number still is increasing, shows that an alternative interpretation is correct: like universities, science academies have strong survival prospects in societies because they are in principle, and often in practice, a demonstrable 'public good'.

Again, as in the case of universities, making sure that a science academy is a real national asset requires considerable effort; the benefits do not simply fall from the sky.

A new academy that adopts and steadfastly maintains a fresh and contemporary approach to its mission within the core framework of practice can readily become a star performer. The argument will be made here that South Africa's national science academy has achieved this status, after only 20 years, despite having had to contend with many difficulties in its operating environment since its inception in 1996.

The process to establish the national academy - the Academy of Science of South Africa (ASSAf) - took about 5 years and was aligned with the momentous events that led to the first democratic election in South Africa in 1994. The nine-member planning team began its memorandum with the following set of assertions:

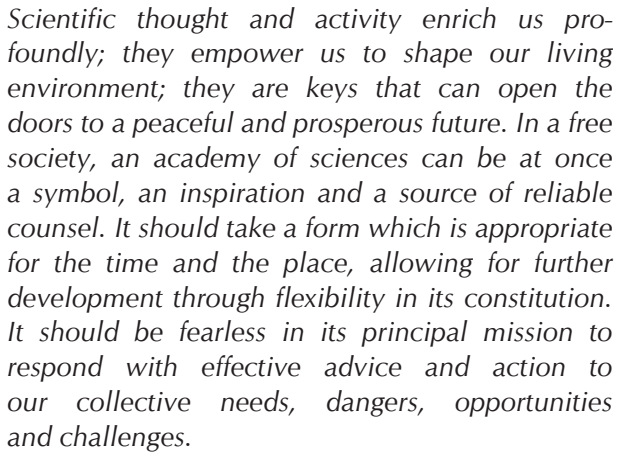

A way was then forged for the new, inclusive academy to be formed, designed to serve all the country's people as captured in the slogan 'science for society'. Parliament passed the ASSAf Act in 2001, 'licensing' ASSAf to receive public funding and to carry out its mission as the sole national science academy, also representing the country internationally in this arena.

ASSAf was intended by its founders (and by its parliamentary sponsors) to retain the best of the global academy tradition, but to be of this time and this place. Thus the constitution adopted by the nascent academy reflected an important principle that allowed ASSAf to jettison many outof-date notions that were still carried forward in the academy tradition by older academies. Amongst these was the idea of academy fellowship or membership being a kind of reward for past academic efforts, a club of 'haves' which looked down on 'have-nots'. Another discarded viewpoint was one which regarded the word 'science' as synonymous with 'natural science' or 'hard science', the preserve of people who regarded themselves as the only 'proper' scientists. Yet another rejected approach was to regard science academies as merely bringing under one privileged roof a number of different disciplines ('the sciences'), all constituting separately communities in each of which the constituent brains have 'constructed' themselves irreversibly into a unique mode of thought.

The newcomer, ASSAf, after considerable debate, and at some risk to its evolving support base, opted for the standpoint that a national 'science academy' should basically be devoted to the promotion and utilisation of the open-ended and evidence-based way of enquiry that is common to all empirical disciplines (hence ASSAf would be an 'Academy of Science', not of 'Sciences'). This approach meant that the distinctive powers of many disciplines would be harnessed to common purpose, at the highest level, to address societal problems - the principal mission of the organisation. The principle also made it logical (although still internationally unique) that elective membership of ASSAf would be based on the double criteria of excellence in science (across the entire disciplinary spectrum) and success in applying such high-level scientific thought for the benefit of society; it was thought that such scholars would find it easier to cross boundaries and relate to one another in a mutually respectful manner in a volunteer system of joint intellectual service.

ASSAf has published the century-old South African Journal of Science since 2002, and launched its science magazine Quest a few years later; both are multidisciplinary, and in their different ways are key vehicles for promoting the same cohesive principle espoused by ASSAf in its 'science-for-society' mission.

A further aspiration, present but not explicitly articulated in the founding decisions of ASSAf, was to avoid the gerontocracy so characteristic of older academies. This was partially addressed by the above-mentioned principles but given substantive form by the creation of the ASSAfaffiliated South African Young Academy of Science (SAYAS) in the second decade of ASSAf's existence.

ASSAf was also determined from the start to break down the infamous 'Limpopo curtain' that had prevented South African scholars from interacting with their northern neighbours and the rest of the continent ASSAf wished to be part of a cooperative regional academy system. The opportunity to embed itself in this way came with the African Science Academy Development Initiative (ASADI) sponsored by the US National Academies from 2005 onwards, providing contact points, joint conferences and projects, and a substantial increase in the number of partner African science academies. The focus of mentoring provided through the initiative by the US National Academies was on best practice in the generation of evidence-based advice, and this assistance underpinned the central role of this activity for the African academies, including ASSAf. Towards the end of its first 20-year period, ASSAf was requested to host two African-region branches of international academy-linked bodies - the Regional Office for Africa (ROA) of the International Council for Science (ICSU), as well as the Regional Office for Sub-Saharan Africa of The World Academy of Sciences (TWAS). The 'Limpopo curtain' is certainly no more...

The value of a fresh approach to ASSAf's agenda was shown in various ways during its difficult setting-up period. In the decade before there was a significant track record of authoritative, evidence-based advice generated in the national interest, ASSAf in its core constituency of wellestablished researchers and scholars appeared, in traditional 'academy terms', to be junior to the two rival but largely sectoral bodies of the 'old South Africa': the Royal Society of South Africa (RSSAf) and Die Suid-Afrikaanse Akademie vir Wetenskap en Kuns (SAAWK), both of which have continued to exist after ASSAf's formation. During the 
second half-century of its existence, the RSSAf had been in decline, with limited resources and influence. SAAWK, by contrast, functioned during the same period as the de facto national science academy of the country, one of the pillars of the Afrikaner-dominated state, recognised and funded by Parliament as a statutory organisation, extensively supported financially by the private sector, but involved in national policy formulation almost entirely 'off the record' and unaccountably. ASSAf, as a differently conceptualised newcomer whose primary purpose was to serve the whole society through scientific thinking across disciplines and not within disciplines, has by now fully established itself in its demonstrable commitment to transparency (all its reports are in the public domain), best consensus arising from multiple perspectives, and high quality as assured by independent and multiple peer review.

It is striking that some of the most influential leaders of advanced country academies began to advocate a shift from the traditional inward-looking focus of such bodies more or less at the time that ASSAf was being established, moving towards the same foregrounding of societal service in the form of consensus advice generated by a full review of available evidence across the disciplinary spectrum. ASSAf was recognised as having pre-aligned itself with this shift, believing firmly that a national science academy in the modern era exists primarily to make possible the efficient and effective mobilisation of a nation's intellectual 'firepower' to address its most urgent problems. It was consequently not a surprise that ASSAf was elected to membership of the first InterAcademy Council (IAC) when this was formed in 2000 to drive the performance of international consensus studies on issues of global importance.

ASSAf's first major consensus report on research publishing in and from South Africa (commissioned by government) was released in 2006 after extensive process guidelines had been developed for ensuring that the panel-based reviews were independent, reflected a best consensus of multiple perspectives, and were of a high scholarly standard (including thorough peer review). This report led to the launching of an ASSAf-led and government-funded programme to improve and support scholarly publishing in multiple ways, including the setting up of the National Scholarly Editors' Forum, acceptance of a National Code of Best Practice in journal editing and peer review, and the launching of a fully indexed, open-access e-platform (SciELO SA) already presenting the full-text of 60 local scholarly journals which have passed scrutiny by discipline-grouped ASSAf peer-review panels. This activity has had, and is still having, a significant and broad impact on scholarly practice in South Africa.

The advisory function espoused by ASSAf is by now also performed in various ways other than full consensus reviews. Well-organised and highly participatory forum-style workshops on problem areas can provide an indication relatively quickly of a 'beginning consensus' on priorities and possible solutions. 'Informed high-level consensus' opinions on key government strategies can be generated in short order by well-constituted expert panels if required urgently. Concise position papers can be released on matters of public controversy or confusion. ASSAf can also act as a channel within the country for the dissemination of consensus reports and advisories emanating from regional or global academy groupings or agencies, such as those produced by the IAC already mentioned. In every case, the ASSAf Council is charged with the final approval-and-release decisions, based on process correctness and scholarly quality: the Council is publicly accountable for maintaining the good reputation of ASSAf but does not 'second-guess' the findings and recommendations of its appointed panels.
One year after the groundbreaking research publishing report, ASSAf on its own initiative produced a consensus report on the evidence base concerning possible nutritional influences on the pandemic diseases caused by chronic HIV and Mycobacterium tuberculosis infection; the findings helped to end a disastrous period of 'HIV denialism' in South Africa and to initiate a concerted national programme of science-based healthcare to mitigate the damage to society and the economy that these diseases were causing. This report was widely reported internationally and acclaimed as a clear indication that Africa's science academies were independently capable of playing a significant role in addressing key issues affecting their societies.

Only 9 years after these two reports and many other consensus reviews, forum proceedings, advisories and position papers later, an ASSAf consensus report on policy issues concerning gender orientation in Africa, prepared in partnership with the Ugandan Academy of Sciences, was praised as courageous and timely in a lead editorial and feature article in Nature. The 'teenage academy' was now deemed worthy of frontline international attention.

In the face of this good record, it is finally necessary to discuss two caveats, the chief causes of concern on the part of ASSAf leadership and its supporters. One is the issue of independence, important for a body that needs government funding to maintain and build its infrastructure, as well as funding on a contractual basis for commissioned reviews or other forms of advice. The principle of accountability makes it appropriate that the use of taxpayer money by an independent (although statutory) academy should require formal proposals, budgets, financial reports and audits, and be assessed against performance. This unavoidably opens up the possibility of top-down control within a system where most other public entities are as clear-cut government agencies subject to such direct control, even within the parameters of their respective statutes. It stands to the immense credit of the government department responsible for ASSAf's public funding, the Department of Science and Technology, and the government more broadly, that they have appreciated the fact that the only good national science academy is an independent one, and have acted accordingly.

The second worry is the still inadequate realisation on the part of researchers in the public sector (universities and research councils), as well as those in the private sector, of the difference between the processes of prospective research into matters of importance, which may or may not create evidence for policy, and the systematic, consensus-seeking review of already available evidence by research-experienced experts with multiple disciplinary perspectives, in ways that are directly designed to provide an evidential basis for policy. While there is no prima facie reason why the second mode of investigation cannot be done in a university or research council setting, it is simply much better and more cost effective when it is performed by an academy which can effectively mobilise any number of appropriately equipped volunteer scholars from any number of skills areas, see to a high level of quality assurance, and ensure transparency, all in a fully accountable manner.

Science academies of the kind that ASSAf aspires to be will be judged mainly on their track records in assisting society. A promising start has been made, and one can justifiably be optimistic about a second 20 -year period of high-level achievement in this sphere.

Wieland Gevers is Professor Emeritus at the University of Cape Town and a past President of ASSAf (1998-2004). 